\title{
Hybrid reactors: Nuclear breeding or energy production?
}

\author{
Mireia Piera , Antonio Lafuente , Alberto Abánades , J.M. Martinez-Val \\ UNED, EISII-Dp Ingenieria Energetica, c/Jwan del Rosal 12, 28040 Madrid, Spain \\ EISII-UPM, cllosé Gutierrez Abascal 2, 28006 Madrid, Spain
}

\begin{abstract}
A B S T R A C T
After reviewing the long-standing tradition on hybrid research, an assessment model is presented in order to characterize the hybrid performance under different objectives. In hybrids, neutron multiplication in the subcritical blanket plays a major role, not only for energy production and nuclear breeding, but also for tritium breeding, which is fundamental requirement in fusion-fission hybrids. All three objectives are better achieved with high values of the neutron multiplication factor $(k$-eff) with the obvious and fundamental limitation that it cannot reach criticality under any event, particularly, in the case of a loss of coolant accident. This limitation will be very important in the selection of the coolant. Some general considerations will be proposed, as guidelines for assessing the hybrid potential in a given scenario. Those guidelines point out that hybrids can be of great interest for the future of nuclear energy in a framework of Sustainable Development, because they can contribute to the efficient exploitation of nuclear fuels, with very high safety features. Additionally, a proposal is presented on a blanket specially suited for fusion-fission hybrids, although this reactor concept is still under review, and new work is needed for identifying the most suitable blanket composition, which can vary depending on the main objective of the hybrid.
\end{abstract}

\section{Introduction and objectives}

Hybrid reactors $[1-30]$ have been considered for decades as potential tools for exploiting the natural nuclear resources in an optimized way. The rationale for that is to use neutrons generated by some independent reactions (notably fusion [1-3] and spallation [31-37]) for sustaining a subcritical fission chain reaction. Basically, this use can be aimed at

- Generating energy in the subcritical reactor $[1,2]$.

- Breeding fissile nuclei from fertile ones (particularly Pu-239 from U-238 and U-233 from Th-232) to be burnt-up in other reactors $[5,6]$.

- Transmuting radjoactive waste, notably transuranium isotopes $[3,36]$.

Theoretically, all three objectives can be pursued in a given installation, but there are some obvious restrictions that must be taken into account in the design of a hybrid. Some of those restrictions stem from the inherent features of neutron-induced reactions, and some others would depend on the type of nuclear energy scenario where the hybrid would have to operate. In this paper, a review is presented about the foreseeable features of hybrids for energy production (at high temperature) and nuclear breeding (at low temperature). Combination of both would always be possible, but the final decisions would have to be taken on the basis on Nuclear Energy Sustainability, which will include considerations on the actual risk of proliferation of the hybrids and their fuel cycles.

Besides that, tritium breeding will be specifically considered for fusion-fission hybrids. [n a pure fusion reactor, it will be difficult to meet this requirement. [n a hybrid, it will be seen that the requirement will become particularly easy for high $k$-effective ( $k$-eff) blankets.

In the following, a review is made on the hybrids literature in Section 2. For the future, any assessment on the hybrid potential has to take into account criteria on Sustainable Development applied to the nuclear field, which are analyzed in Section 3 . Section 4 presents a model for hybrid performance analysis, where the neutronic cycle is an essential element. As a case study, a proposal for fusion hybrid blanket is presented in Section 5, as an instance for applying the guidelines of the general systematics, particularly in relation to coolant selection, because of the reactivity effects of the coolant. Section 6 is devoted to summarize the analysis and to point out futures work to be done for identifying the most suitable design windows for hybrid development.

\section{A bibliographical review of hybrids}

Hybrids were mainly proposed in the 1970 s of the previous Century for several reasons, including the fact that Nuclear Fusion 
started to be considered as a lengthy process of R\&D needing a long time span and very huge budgets. Hybrids $[1-26]$ seemed to be a potential way to shorten the road for getting energy from fusion. However, hybrids needed a parallel strong development on nuclear fission blankets, including new fuels and new reprocessing techniques, and such programs were not developed, because of the strong cut in Fission R\&D after 1980. Anyhow, the Hybrid concept remained as a potential tool for getting the best of both domains, fusion and fission, without needing a full development of fusion reactors, and without using critical reactors, which present more problems on safety than subcritical reactors. The interest of hybrids for being combined with Generation- 3 reactors has been analyzed recently [27] taking into account the very high safety leve] of these reactors, and the enormous capability of hybrids to breed fissile material. In fact, this capabilicy, as energy generation in the blanket, can also be exploited by any subcritical assembly driven by a strong energy source, notably a spallation source [28-33]. Another goal that could be reached with hybrids is the incineration of nuclear waste [34-36]. This is very important because the existence of nuclear waste along very many Centuries is a fact that has hampered the development of nuclear energy [37]. When reviewing so many evaluations and calculations on Nuclear Hybrids, one concludes that the so called Nuclear Renaissance will also have to consider them as relevant tools for the future.

\section{Nuclear Energy Sustainability}

A proposal for sustainability technical criteria in nuclear energy [38-40] can be established as follows:

- Enhanced safety in nuclear reactors and nuclear fuel facilities.

- High-level exploitation of natural nuclear materials.

- Minimization of the radioactive inventory in the waste.

- Development of proliferation resistant technologies.

The last point seems to be very critical for the future of nuclear energy in a large scale [41], and it could dominate the definition of $R \& D$ activities in the future, both about reactors and fuel cycles. However, this is mainly a political and diplomatic problem, and it can be said that in all countries having nuclear weaponry, the military program was not taking any benefit from the civilian program (in some countries, there were not any civilian program). Nevertheless, developing proliferation-free facilities would ease a lot a larger deployment of civilian nuclear energy.

On the other hand, limitations in mineral reserves led to the concept of sustainability of energy in a finite world [42] although the very concept of Sustainable Development needed some more time to be formulated [43]. Anyway, the key for addressing this challenge is how to propose and develop new technologies for properly exploiting the available resources. In the case of nuclear energy, this quest has produced several proposals on critical reactors [44-46] but Hybrids are still out of main stream research, and an effort must be made from Hybrids proponents in order to convince the scientific community and policy makers that Hybrids deserve a good deal.

Current commercial reactors are not good in exploiting the nuclear natural resources. They barely burn $0.6 \%$ of them. Reaching a percentage approaching $100 \%$ will need breeders, and this is a formidable challenge, because critical fast reactors could suffer from some reactivity effects [47] leading to positive feedback between thermal-hydraulics and nuclear power, which can produce exceedingly large power surges. When the coolant density decreases, eventually until zero in an accident, two effects increase the reactivity of the reactor: the neutron spectrum hardens, because of a lower moderation effect; and the neutron capture rate decreases, because of the absence of an absorbing material (the coolant).

Hybrids are very appealing machines in this context because they can be designed to remain subcritical even in severe accidental conditions, as full void of the molten metal acting as core coolant. Although sodium was the standard choice for fast reactors [39], lead has become an interesting alternative, although it also conveys the problem of a positive reactivity coeficient or coolant voids and reduction in density. of course, this problem is much less severe in a hybrid, as the Energy Amplifier [31] but the problem of positive feedback still exits.

In the following, a systematic approach to hybrids is presented, which can be a tool for assessing the advantages and drawbacks for different conceptual designs devoted either to energy production or fissile breeding, although both phenomena would always occur in a hybrid, but it can be specialized for one of the aims [26], according to the scenario devised for the quest of Nuclear Energy Sustainability.

\section{Systematic approach for hybrid performance analysis}

A sketch of the hybrid phenomenology is depicted in Fig. 1, which is applicable either for spallation neutron sources or for fusion devices. The core of those phenomena is the subcritical multiplication of the neutron population, which drives the reaction rates and the power production. In Fig. 2, a sketch is presented on the neutron-induced reactions in a hybrid. Of course, the essential companion of the neutrons is the composition and configuration of the material of the subcritical assembly. In a first approach, they can be similar, for not to say equal, to the composition and configuration of critical fast reactors.

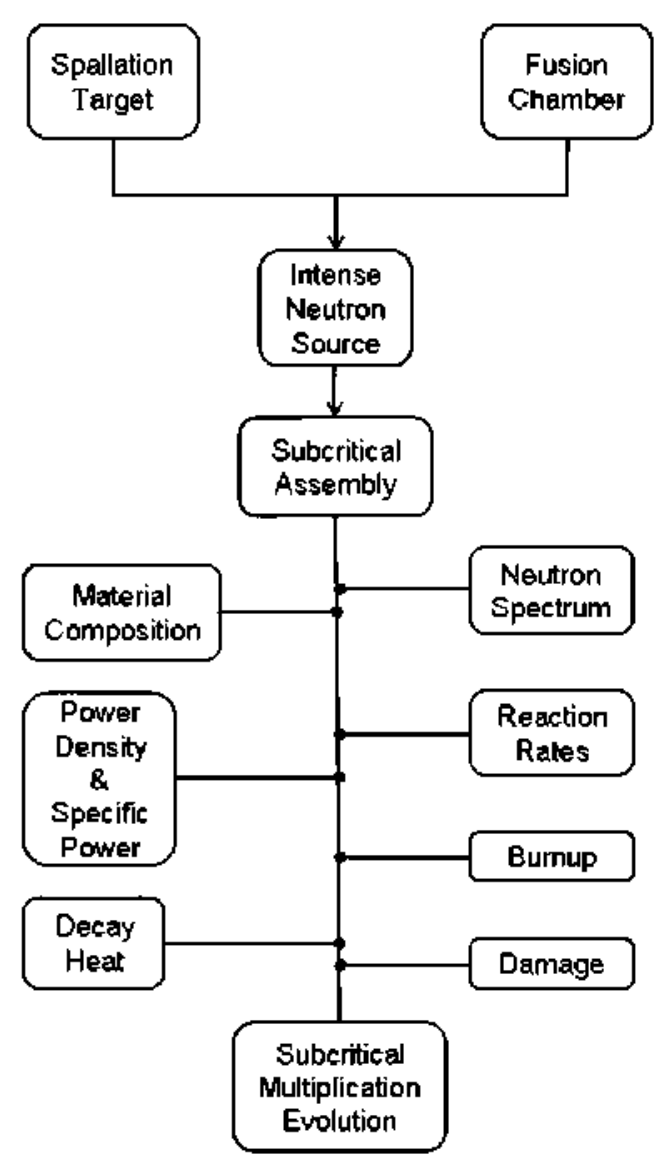

Fig 1. A schematic view of the main topics for the analysis of a hybrid blanket 


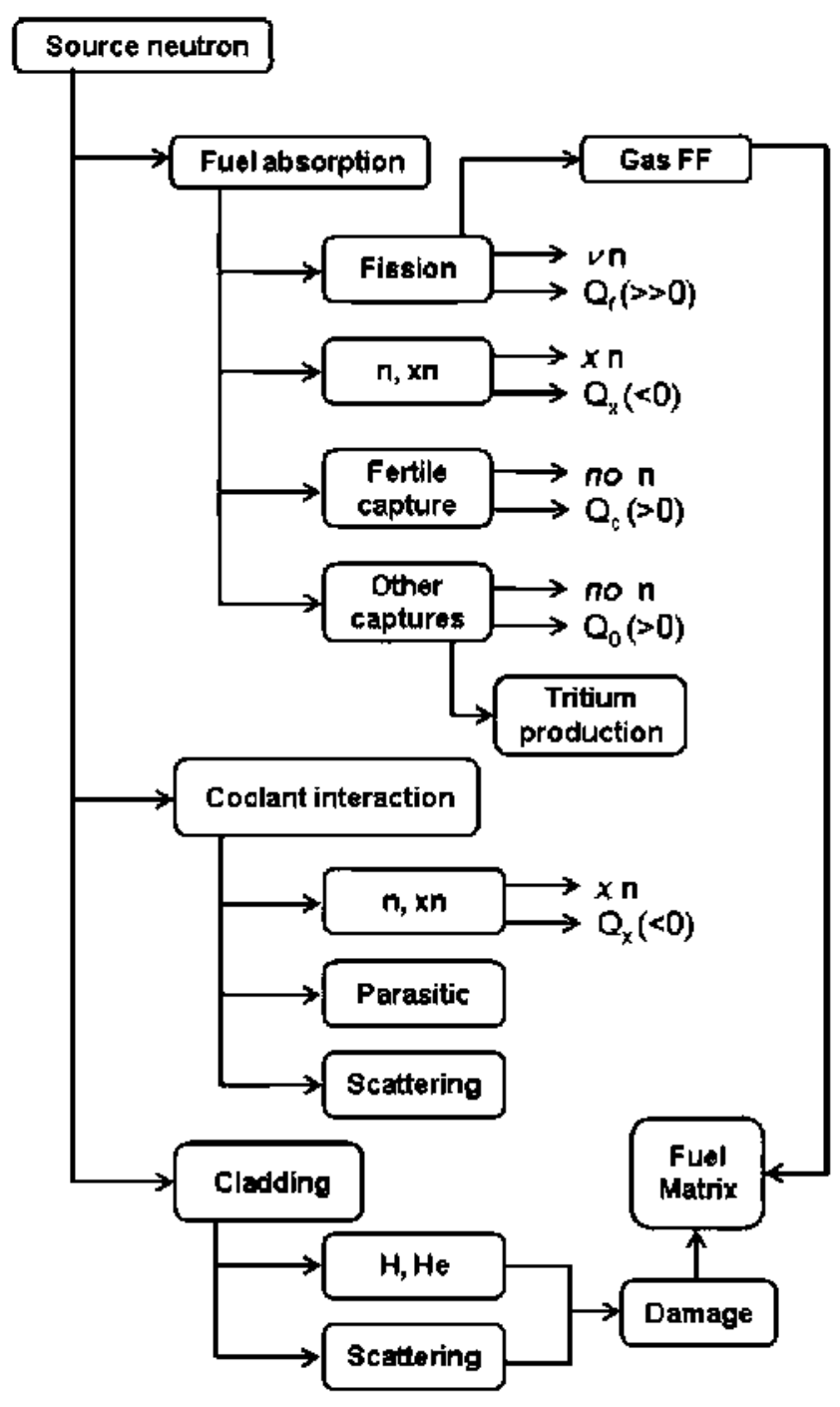

Fig. 2. Neutron-induced reaction tree to guide specific calculations of hybrid blankets.

However, a possibility in the hybrid performance is to keep it at low temperature, with moderate power density, in order to minjmize the effects of loss of coolant accidents [27]. Of course, the only goal in this case would be fissile breeding, to be burnt-up in other reactors, notably Gen 3 ones, which seem to have very high safety standards.

This could be a way to satisfy the requirements formerly cited on Nuclear Energy Sustainability. A more ambitious concept would be to produce energy in the subcritical assembly with very high temperature for having a high conversion efficiency, and to breed fissile fuel both for replacing the spent fuel in the reactor, and to discharge part of it for reprocessing and preparation of new fue] elements for other reactors, either critical or subcritical. In this case, the risk of thermal accidents would be higher than in the previous case, because the specific power and the power density would be much higher than in Gen 3 reactor, which can be considered as the reference about safety.

There could be an alternative to the previous case, if fissile breeding is just aimed at keeping the k-effective of the blanket in close-to-constant value, so that all magnitudes remain also constant. No fissile breeding would be bred for selling to other reactors. This alternative is the one followed in the LIFE project [48] and it would not need reprocessing, which could be a very positive feature from the viewpoint of proliferation resistance, but it will be limited by cladding and fuel damage as a result of jrradjation. In particular, gaseous products generation will represent a very severe problem for achieving high burnups. One option for making it compatible high temperature and long fuel resistance to radiation damage is to adopt pebbles beds made of TRISO particles [49-55] but they also have important limitations in working temperature and maximum burnup, and there is a clear correlation of the value of those magnitudes with the probability of fission products release [53-55].

The three alternatives presented cannot be evaluated as general proposals, because they will depend a lot on the composition used in each case. They would also depend on the general economic and international scenario, because having or not having commercial reprocessing will represent a big change in the evaluation criteria, and that point will mainly be related with the proliferation problem.

of course, a high exploitation of the natural resources would need reprocessing and recycling, and this point has to be properly counterbalanced against the risk of proliferation posed by a given fuel cycle. A difficult point in this context is that the No-proliferation criterion has a lot of political weigh, and the goal of exploiting the resources is mainly economical.

Waste is also important in the same balance, because the amount of waste per unit of generated energy will be lower in closed cycles with high burnups and actinide recycling. This is in connection to reprocessing, but is also in connection to safety, because of the nuclear properties of higher actinides. In particular, they have much lower values of the fraction of delayed neutrons, as compared to U-235, which is very negative for reactivity control.

This fact is another important reason for the evaluation of the hybrids to be very dependent on the blanket composition. Similarly, coolant composition is also of fundamental concern for the power stability in the blanket. Moreover, the blanket must not reach criticality under any condition, including loss of coolant accidents. This fundamental requirement will be analyzed in the case study of the following section.

On the other hand, the blanket $k$-eff also dominates the problem of tritium breeding. It is seen in Figs. 3 and 4 that the higher the $k$ eff value, the smaller the fraction " $m$ " of neutrons absorbed in the Li-6 of the blanket to produce tritjum. This is an advantage because a higher fraction of neutrons are absorbed in the fuel, either producing energy (through fission) or breeding new fissile nuclei (by fertile capture).

\section{A case study: a conceptual proposal for fusion-fission hybrid blanket}

In addition to the former requirements already commented, a fusion hybrid must also breed tritjum, which is mainly done through the neutron capture in $\mathrm{Li}-6$, which is the less abundant of the natural $\mathrm{Li}$ isotopes. This capture is actually very relevant for thermal neutrons, with a cross-section of 500 barns for $0.1 \mathrm{eV}$. This requirement is to some extent in contradiction with the fast spectrum needed to breed fissile fuel.

At the same time, the problem of the reactivity feedback must also be taken into account, which is mainly related to the non-negligible neutron capture in sodium (Na-23) or in lead (or $\mathrm{Pb}-\mathrm{Bi}$ ) which are considered as the suitable coolants for fast spectrum blankets.

In our proposal, we have considered the most relevant data of the nuclei that could be candidates for hybrid coolant (and tritium breeding). They are gathered in Table 1 .

Cross-sections (XS) are given in barns, booth for elastic scattering (el) contributing to moderation (composed with the lethargy 


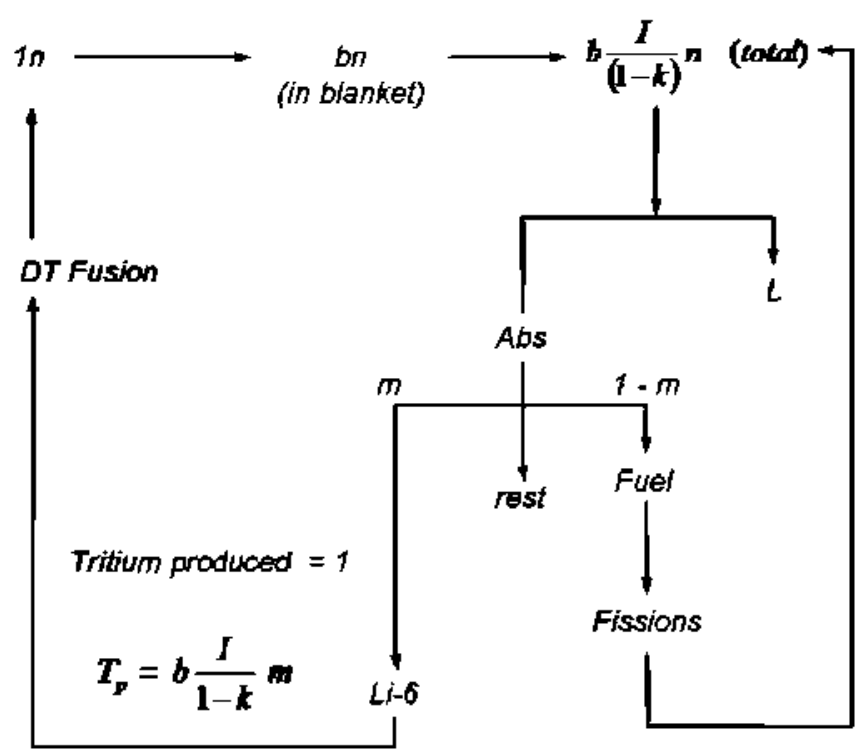

Fig. 3. An outline of the neutron cycle in a fusion hybrid. " $b$ " is the fraction of fusion-born neutrons which enter into the blanket; " $\Gamma$ " is the importance of the fusion neutrons for the subcritical blanket (see Ref. [26]) and it is slightly above 1. " $i$ " stands for leakage. Neutrons which do not leak (the majority of them) are absorbed inside the reactor, mainly in the fuel. " $m$ " is the fraction of neutrons captured in Li- 6 to produce tritium. The blanket must produce a tritium atom per fusion happened in the fusion chamber.

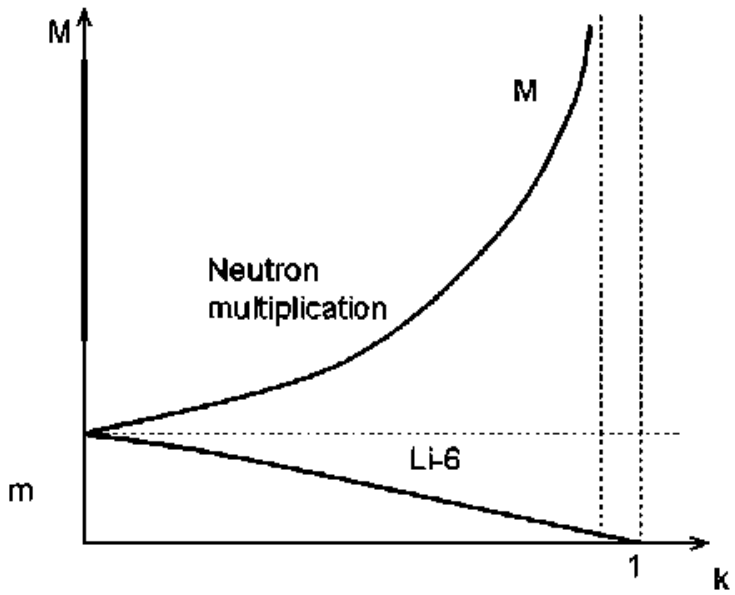

Fig 4. Dependence of the total neutron multiplication, $M$, in a fusion hybrid, versus $k$-effective of the blanket. It is also depicted the value required in " $m$ " to meet the tritium breeding condition, " $m$ " being the fraction of neutrons absorbed in Li- 6 .

Table 1

Some relevant parameters of the neutron interaction with some nuclei that can be components of coolant (XS: cross-section, in barns; el: elastic scattering: c: capture).

\begin{tabular}{lllll}
\hline Nuclei & Lethargy gain & XS el & XS c 0.1 eV & XSc 100 eV \\
\hline L-6 & 0.30 & 0.75 & 500 & 13 \\
L-7 & 0.26 & 1 & 0.02 & 0.0008 \\
Be-9 & 0.21 & 6 & 0.004 & 0.0001 \\
C-12 & 0.15 & 4.8 & 0.002 & 0.00003 \\
F-19 & 0.10 & 3.5 & 0.005 & 0.0002 \\
Na-23 & 0.086 & 2 & 0.3 & 0.01 \\
\hline
\end{tabular}

gain, which is a parameter featuring the kinetic energy loss of the neutron іл ал elastic scattering) and capture (c) which depends a lot on neutron energy. It is clearly seen that $\mathrm{Na}-23$ has a fairly large XS of capture as compared to F-19 and Be-9 (C-12 has bеeл in- cluded only as a moderation reference, but it must be taken into account that a lot of $C$ is needed in a thermal reactor for having complete moderation)

The case study is to consider $\mathrm{F}_{2} \mathrm{Be}$ as molten salt coolant, in amounts as small as possible for cooling [57], which would produce a relatively fast spectrum in the inner part of the blanket, mainly devoted to produce energy and breed fissile fuel. An outer part of the blanket would have a thermal spectrum to breed tritium in $\mathrm{Li}_{2} \mathrm{O}$ solid pins. Although a molten salt of the type FliBe has been proposed for that purpose in the LIFE initiative, the Li-6 effect on the reactivity coefficient will still be more positjve than that of Na-23, so being a source of power oscillations and other instabilities.

The $\mathrm{F}_{2} \mathrm{Be}$ molten salt as coolant will have another advantage: the neutron multiplication effect by $(n, 2 n)$ reactions in Be. This reaction has an effective threshold of $2.5 \mathrm{MeV}$ (the theoretical one is 1.85 ) above which the cross-section value is 0.5 barns, pretty high a value for such neutron energies. In comparison, $\mathrm{Na}-23$ has a $(n, 2 n)$ cross-section of 0.07 barns with an effective threshold of $15 \mathrm{MeV}$, which represent a negligible effect on the neutron есоnomy of a reactor. However, $\operatorname{Be}(n, 2 n)$ reactions contribute to some extent to neutron multiplication, and the net effect of Be on the neutron economy сал be positive for fast or very fast spectrum, which in turn would be very safe for the stability of the reactor, in the sense that a loss of coolant (Be) would convey a reduction іл the лeutron flux, and therefore a reduction in the reactor power. However, the moderation effect of Be makes it difficult to conform a truly fast spectrum, and the neutron multiplication in Be can be relatively small. This fact has to be analyzed with accurate calculations, as will be seen later on with ал example.

$\mathrm{F}_{2} \mathrm{Be}$ has a melting point of $554{ }^{\circ} \mathrm{C}$ and a boiling point of $1169^{\circ} \mathrm{C}$. Aл appropriate range of working temperatures would be around $600^{\circ} \mathrm{C}$ (with ал uncertainty of $20^{\circ} \mathrm{C}$ ) which is higher than the standard range for molten metal fast reactors, but lower than the value of Lif alone. This salt has a melting point of $845^{\circ} \mathrm{C}$, and has to be mixed with $\mathrm{F}_{2} \mathrm{Be}$ to get a suitable molten salt coolant. other alternative to $\mathrm{F}_{2} \mathrm{Be}$ could be considered as molten salt coolant, particularly $\mathrm{Cl}_{2} \mathrm{Be}$, with a melting point of $399^{\circ} \mathrm{C}$, but a very close boiling point, at $482^{\circ} \mathrm{C}$. Moreover, from the лeutronic point of view, the presence of $\mathrm{Cl}$ poses very severe problems, because its main isotope, $\mathrm{Cl}-35$, has a sizeable value of the capture crosssection, of 0.22 barns for $100 \mathrm{eV}$ neutrons. It is therefore not acceptable as a part of the coolant, because of its very high positive feedback of $\mathrm{Cl}$-coolant voids in the neutron flux and thermal power.

The same was already said about $L i$, notably $\mathrm{Li}-6$, which is the relevant one for tritium breeding. The proposal from our analysis is to allocate the required $\mathrm{Li}$ in solid and cladded form, as $\mathrm{Li}_{2} \mathrm{O}$, for instance. Tritium produced inside the pins could be extracted after discharge. This option would also have the advantage of keeping tritium ( $\mathrm{H}-3$ ) inside a confined space, which is one of the key safety points in Fusion reactors.

Fig. 5 depicts a scheme of a blanket according to the foregoing guidelines. The іллег part of the blanket would be mainly dedicated to neutron multiplication, power generation and fissile breeding, while an outer part of the blanket would have a thermal or epithermal spectrum (including an additional moderator, if needed) and would be devoted to $\mathrm{H}-3$ breeding with some additional neutron multiplication. Another potential goal that could be pursued in the outer part would be thorium (to U-233) breeding [56], and this is another fundamental objective of sustainability, because of the large amounts of Th reselves as compared to those of natural uranium. Additionally, the presence of U-232 accompanying to U-233 poses very large difficulties to reprocessing this fuel, and it is considered a main deterrence against diversion of that material for лол-сіvilian applications. Hence, if a Pu economy 


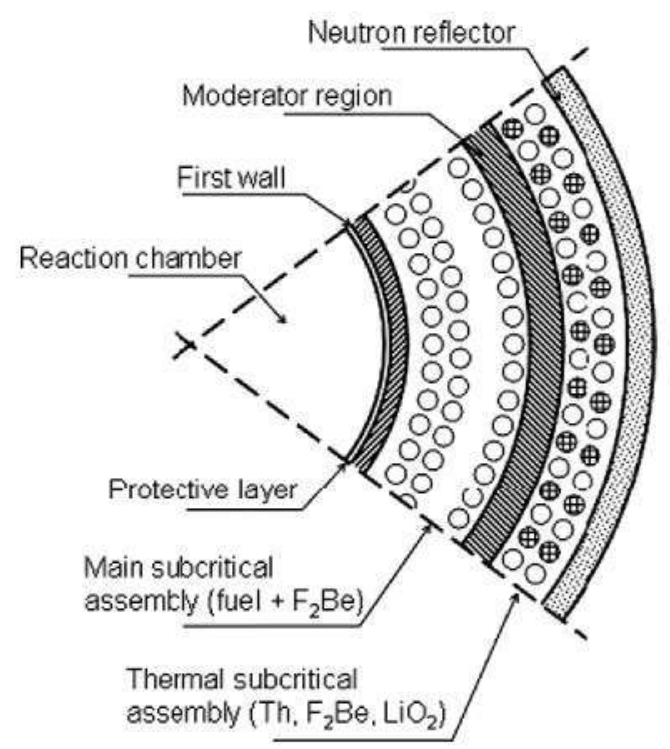

Fig. 5. A cross-section view of a proposed blanket for a fusion hybrid, with devoted regions.

at a large scale is considered a severe threat, the alternative of mixing both fuels ( $U$ and $T h$ ) could be a solution for relaxing that requisite of security.

Although the theoretical approach can be based on the foregoing general considerations on the cross-sections of the selected nuclei, some numerical calculations are needed to assess the suitability of this idea. Of course, detailed numerical calculations would be needed for a specific hybrid design, which in turn would need a design of the fusion chamber and surroundings, which is not available yet. The analysis carried out at this level has been based on a generic hexagonal lattice of cladded fuel pins, with different types of coolant, namely molten salts (FLiBe and $\mathrm{F}_{2} \mathrm{Be}$ ) and molten metals $(\mathrm{Na}$, and $\mathrm{Pb})$. The clad outer radius is $0.5 \mathrm{~cm}$, with a thickness of $0.5 \mathrm{~mm}$, and the pin pitch has been fixed in $1.2 \mathrm{~cm}$, although this parameter would have to be studied in connection to the coolant performance. The fuel composition corresponds to a mixture of $U$ and Pu oxides, with a content of Pu of $10 \%$ as related to $\mathrm{U}$, which is depleted uranium (99.7\% of $\mathrm{U}-238$ and $0.3 \%$ of $U$ 235). Composition of $\mathrm{Pu}$ corresponds to a typical discharge from LWR (67\% Pu-239, 28\% Pu-240, 4.5\% Pu-241 and 0.5\% Pu-242). This fuel composition should be changed for exploring other regimes and for optimizing the performance according to different criteria, but it is a typical fuel for fast reactors.

A fundamental result is presented in Fig. 6, depicting the variation of the neutron multiplication factor $k$ in an infinite array of hexagonal lattice cells as those described in the text, as a function of the coolant density, for the selected coolants.

It can be seen that molten metals allow for higher values of $k$ infinity at normal condition ( $100 \%$ coolant density) but $\mathrm{F}_{2} \mathrm{Be}$ is slightly better than FLiBe. The reason for these results is the moderation effect produced by $\mathrm{Li}$ and $\mathrm{Be}$. In general, the smaller the $\mathrm{A}$ number of the nuclei, the stronger the moderation effect. Additionally, it is also important the effect of Li-6 captures. From the point of view of safety criteria, it is obvious that the fuel used in the blanket has to remain subcritical under any condition. This is why Fig. 6 is so relevant (although a more accurate picture can be calculated for a given reactor with definite geometry). It is seen that the maximum $k$-eff corresponds to the case with a complete loss of coolant, and it is below 1 in this case of the hexagonal lattice in an infinite array. This conveys maximum values of $k$-eff in operating conditions, for each coolant. Sodium is the one permitting the highest

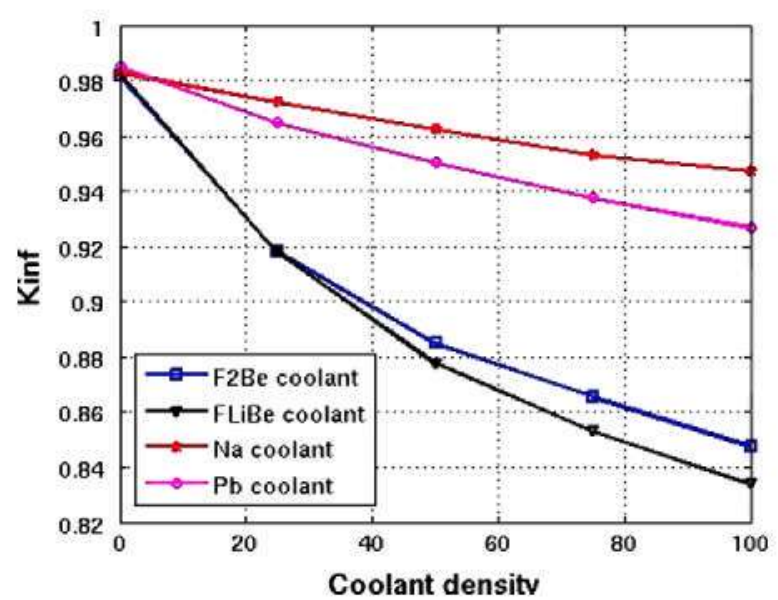

Fig. 6. Variation of $k$ in an infinite array of hexagonal lattice cells as those described in the text, as a function of the coolant density (in percentage of the nominal density) for the selected coolants. Zero percent of coolant density corresponds to total loss of coolant in the reactor.

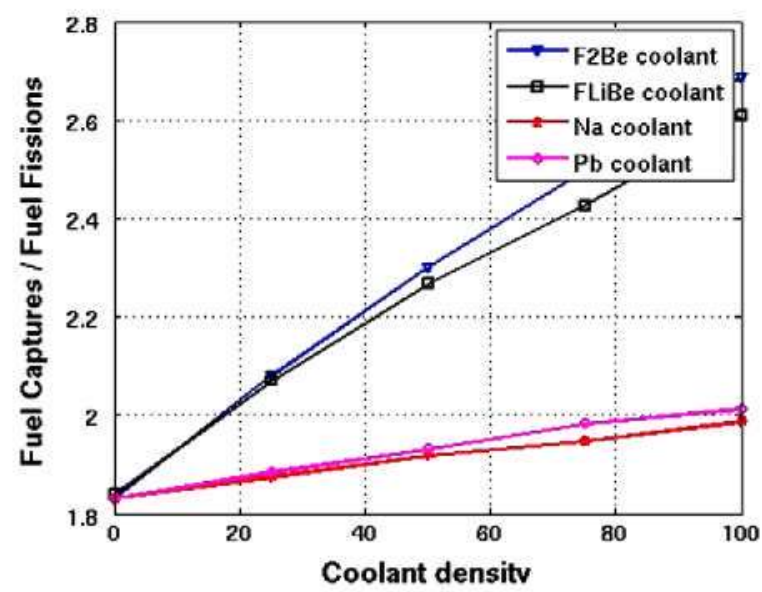

Fig. 7. Variation of the capture/fission ratio in an infinite array of hexagonal lattice cells as those described in the text, as a function of the coolant density (in percentage of the nominal density) for the selected coolants. Zero percent of coolant density corresponds to total loss of coolant in the reactor.

value (0.947) and FLiBe has the minimum one (0.833). Nevertheless, those values have to be checked against the cooling performance, because the volume fraction needed for cooling is not the same for all coolants, but it is a clear instance of the application of the safety criterion related to reactivity.

The former data must be complemented with those of Fig. 7 , where the capture to fission ratio is shown. A high value of this ratio is a clear indication of the nuclear breeding capability of the hybrid. In the case of considering the hybrids for that goal (as fuel factories for Generation-3 reactors [27]) it is very important to have a high value in this ratio. The highest one in our analysis corresponds to $\mathrm{F}_{2} \mathrm{Be}$, which is a very positive feature for this coolant, although it has to be counter-balanced with the $k$-eff value, that must also to be as high as possible for having a good enough neutron multiplication.

\section{Summary and future work}

Hybrids present a wide range of performance possibilities and can therefore be a powerful tool for the deployment of nuclear energy in a much larger scale than today. For going towards that goal, 
some Nuclear Sustainability criteria must be met, as discussed previously. From the technical point of view, it is very important to achieve a very high percentage of exploitation of the raw nuclear materials (U and Th) which is currently a mere $0.6 \%$ for the former and $0 \%$ for the latter; but it must be done in a system of very high safety standards. For both purposes, hybrids present a very good potential, although it must be analyzed properly, as was sеeл in the former case study.

Although many papers on hybrids were published years ago, much more work must be done on many lines, including the selection of fuel (including the Th cycle) and the final selection of coolant for a given purpose.

Іл spite of the pending work, it could be said that a very complete answer to Nuclear Sustainability would be to generate power and to breed fuel for additional reactors in a hybrid blanket, also producing the required tritium, using a mixed fuel cycle with $U$ and Th. The properties of neutron interaction with some relevant nuclei are particularly suited for being exploited in a hybrid sселагіo.

\section{References}

[1] leonard Jr BR. A review of fusion-fission (hybrid) concepts. Nucl Techno 1973;20:161.

[2| Powell C. Hahm DJ. Energy balance of a hybrid fusion-fission reactor. Atomkernergie 1973;21:172.

|3| lidsky LM. Fusion-fission systems: hybrid symbiotic and augean. Nucl Fusion 1975:15:939.

[4] Harms AA. Hierarchical systematics of fusion-fission energy systems. Nucl Fusion 1975; 15:989.

[5] Harms AA, Gordon CW. Fissile fuel breeding potential with paired fusionfission reactors. Ann Nucl Energy 1976;3:411.

|디 Cook NG. Maniscalco JA. Uranium-233 breeding and neutron multiplying blankets for fusion reactors. Nucl Technol 1976;30:5

17| Blinkin Vl. Novikov VM. Symbiotic system of a fusion and a fission reactor with very simple fuel reprocessing. Nucl Fusion 1978;18:7.

[8] Bethe HA. The fusion hybrid. Phys Today 1979;5:44.

[9| Bender DJ. Performance parameters for fusion-fission power systems. Nucl Technol 1979;44:381.

[10] Youssef $M Z$ et al. Tritium and fissile fuel exchange between hybrids, fission power reactors and tritium produce reactors. Nucl Technol 1980;47:397.

[11] Presley ]K et al. Nuclear fuel trajectories of fusion-fission symbionts. Nucl Sci Eng 1980;74:193.

[12] Abdel-khalik SI et al. Impact of fusion-fission hybrids on world nuclear future. Atomkernenergie 1981:38:1.

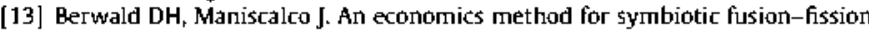
electricity generator systems. Nucl TechnolfFusion 1981:1:128.

(14] Rose RP. The case for the fusion hybrid. J Fusion Energy 1981:1:185.

[15] Lee JD, y Moir RW. Fission-suppressed blankets for fissile fuel breeding fusion reactors. J Fusion Energy 1981:1:299.

[16] Greenspan E. Miley GH. Fissile and synthetic fuel production ability of hybrid reactors. Atomkernenergie 1981:38:12.

[17] Taczanowski 5. Neutron multiplier alternatives for fusion reactor blankets. Ann Nucl Energy 1981:8:29.

[18] Harms AA, Heindler M. Nuclear energy synergetics. New York: Plenum Pub. Co: 1982.

[19] Moir RW. The fusion breeder. J Fusion Energy 1982;2:351.

[20] Moir RW et al. Fusion breeder reactor design studies. Nucl TechnolfFusion 1983:4:589.

[21] Lee JD. U5-DOE fusion breeder program-blanket design and system performance. Atomkernenergie 1984:44:35.

[22] Piet SJ. Safety evaluation of the blanket comparison and selection study. Fusion Technol 1985:8:77.

[23] Garber J, Maya I. Safety assessment of the fusion breeder. Fusion Technol 1985:8:474.
[24] Piera M. Martínez-Val JM. Neutronic characterization and analysis of performance of fusion-fission hybrids. Kerntechnik 1987;50:197.

|25| Martínez-Val JM. Piera M. Nuclear fission sustainability with hybrid nuclear cycles. Energy Convers Manage 2007:48:1480-90.

[26] Van Atta CM, lee JD. Heckrotte W. The electronuclear conversion of fertile to fissile material. Lawrence Livermore Laboratory Report UCRL-52144; 1970.

[27] Takahashi $\mathrm{H}$ et al. Fissile fuel production by linear accelerator. Trans Am Nucl Soc 1982:43:138.

|28| Sahin 5. Neutronic análisis of fast hybrid thermoionic reactors. Atomkernenergie 1981;39:41.

|29| Rubbia C et al. Conceptual design of a fast neutron operated high power energy amplifier. CERN/AT/95-44: 1995.

[30] Andriamonje $5 \mathrm{et}$ al. Experimental determination of the energy generated in nuclear cascades by a high energy beam. Pliys Lett B 1995;348:697.

131] Accelerator-driven systems (ads) and fast reactors ( $\mathrm{fr}$ ) in advanced nuclear fuel cycles. Nucl Energy Agen, OECD; 2002.

[32] Arnould $\mathrm{H}$ et al. Experimental verification of neutron phenomenology in lead and transmutation by adiabatic resonance crossing in accelerator driven systems. Phys lett B 1999;458:167.

[33] Abănades $A$ et al. Results from the TARC experiment: spallation neutron phenomenology in lead and neutron-driven nuclear transmutation by adiabatic resonance crossing. Nucl Instr Methods A 2002;478:577.

[34] Rubbia C, Buono S, Kadi Y, Rubio JA. Fast neutron incineration in the energy amplifier as alternative to geological storage: the case of Spain. CERN/LHC/97$01 ; 1997$.

|35| Advanced nuclear fuel cycles and radioactive waste management. Nucl Energy Agen, OECD; 2006.

[36] NEA-OCDE. Nuclear energy in a sustainable development perspective; 2000. <www.nea.fr/html/pub/webpubs/welcome.html>

[37] Sustainable nuclear energy technology plantform; 2008. <www.snetp.eu>

$|38|$ US.DOE: the path to sustainable nuclear power, <www.er.doe.gov/bes/reports' files/PSNE_rpt.pdfs.

139| Arms Control Center. The limited proliferation-resistance benefits of the nuclear fuel cycles of $\mathrm{AFCl} ; 2006$. <wWw.armscontrolcenter.org/archives' 001711.phps.

[40] Hafele W. Energy in a finite world. Paths to a sustainable future. Energy in a finite world. A global system analysis. Cambridge (MA): Ballinger Pu. Co.; 1981

|41| Brundtland G. Chairman, world commission on environment and development. Oxford, United Kingdom: Our Common Future (The Brundtland report) Oxford University Press; 1987.

|42| CEA. Systems nucleaires du future. Generation IV. Clefs, no. 55; 2007.

43] NEA-OECD. lnnovation in nuclear energy technology. OECD; 2007.

[44] IAEA. Guidance for the evaluation of innovative nuclear reactors and fuel cycles: report of phase IA of the Intemational Project on Innovative Nuclear Reactor's and Fuel Cycles (INPRO), IAEA-TECDOC-1362; 2003.

|45| Storrer $F$. Introduction to the physics of fast power reactors. IAEA series no. 143 , Vienna; 1973.

|46| LIFE project. <http://lasers.llnl.gov/missions/energy-for-the-futureflifes.

[47] The high temperature reactor and nuclear process heat applications. Nucl Eng Des 1984;78 [special issue].

|48| Kugeler K. Schulten R. Hochtemperaturreaktortechnik. Springer Verlag; 1989.

[49] Kugeler $K$, Philippen PW. The potential of self-acting safety features of high temperature reactors. Kerntechnik 1996:61:5.

[50] Lohnert $\mathrm{G}$. Technical design features and essential safety-related properties of the HTR Module. Nucl Eng Des 1990;121:259.

[51] Krueger K, Bergerfurth A, Burger S, Pohl P, Wimmers M, Cleveland JC. Preparation conduct and experimental results of the AVR Loss of coolant accident simulation test. Nucl Sci Eng 1991;107:99.

[52] Heit W, Huschka H. Status of qualification of HTGR fuel element spheres. Nucl Technol 1985;69:44.

[53] Sawa K et al. Safety criteria and quality control of HTR fuel. Nucl Eng Des 2001;208:305.

[54| IAEA. Fuel performance and fission products behaviour in gas cooled reactors. IAEA-TECDOC-978; November 1997.

|55| Thorium fuel utilization: options and trends. In: Proceedings of three IAEA meetings held in Vienna in 1997, 1998 and 1999. IAEA-TECDOC-1319.

[56] Martínez-Val JM, Piera M. Reactor nuclear heterogéneo con compuestos de berilio como refrigerante. Patent application, ES2008001471. 